\title{
Impact of birch xylan composition and structure on film formation and properties
}

\section{Morais de Carvalho, Danila}

2020-02

Morais de Carvalho, D, Marchand, C , Berglund, J , Lindström , M E, Vilaplana , F \& Sevastyanova , O 2020 , ' Impact of birch xylan composition and structure on film formation and properties ' , Holzforschung : international journal of the biology, chemistry, physics and technology of wood, vol. 74 , no. 2 , pp. 184-196 . https://doi.org/10.1515/hf-2018-0224

http://hdl.handle.net/10138/315090

https://doi.org/10.1515/hf-2018-0224

unspecified

acceptedVersion

Downloaded from Helda, University of Helsinki institutional repository.

This is an electronic reprint of the original article.

This reprint may differ from the original in pagination and typographic detail.

Please cite the original version. 


\title{
Impact of birch xylan composition and structure on film formation and properties
}

\author{
Danila Morais de Carvalho ${ }^{\mathrm{a}, \mathrm{b}^{*}}$, Célia Marchand ${ }^{\mathrm{a}, \mathrm{c}}$, Jennie Berglund ${ }^{\mathrm{d}}$, Mikael Lindströmm ${ }^{\mathrm{a}, \mathrm{d}}$, \\ Francisco Vilaplana ${ }^{\mathrm{d}, \mathrm{e}}$, Olena Sevastyanova ${ }^{\mathrm{a}, \mathrm{d},{ }^{*}}$
}

${ }^{a}$ KTH Royal Institute of Technology, Department of Fibre and Polymer Technology, Division of Wood Chemistry and Pulp Technology, Stockholm 100 44, Sweden

${ }^{\mathrm{b}}$ University of Helsinki, Department of Food and Nutrition, Faculty of Agriculture and Forestry, Helsinki 00790, Finland

${ }^{\mathrm{c}}$ Grenoble INP-Pagora, Graduate School of Engineering in Paper, Print Media and Biomaterials, 38402 Grenoble, France

${ }^{\mathrm{d}}$ KTH Royal Institute of Technology, Department of Fibre and Polymer Technology, Wallenberg Wood Science Center, Stockholm 100 44, Sweden

${ }^{e}$ KTH Royal Institute of Technology, AlbaNova University Center, Division of Glycoscience, Stockholm 106 91, Sweden

* Corresponding authors at: Department of Fibre and Polymer Technology, KTH, Royal Institute of Technology, SE-100 44 Stockholm, Sweden.

E-mails: dmdc@kth.se (D.M.de Carvalho), olena@kth.se (O. Sevastyanova).

\begin{abstract}
Commercial birch xylan (CX) and alkali-soluble birch xylan (ASX) were subjected to controlled acetylation and used for film formation in the presence $(20 \%$ and $40 \%)$ or absence of plasticizers (i.e., glycerol, sorbitol and xylitol). Although the content of Klason lignin was similar (1.2-1.4\%), the acetylation process was favored by the high-purity CX ( $97 \%$ xylan) over the ASX ( $89 \%$ xylan). On the other hand, the presence of residual pectin heteropolysaccharides rather than xylan in the ASX sample was beneficial for film formation. These heteropolysaccharides seemed to act as natural plasticizers during film formation, allowing the formation of coherent films from ASX, even in the absence of an external plasticizer. The use of plasticizer favored the mechanical properties of films, especially in a dosage of $40 \%$, when plastic behavior was created. Acetylation favored the film formation and slightly improved the mechanical properties of the films and this improvement was in the same range of that achieved when using $20 \%$ plasticizer in non-acetylated
\end{abstract}


ASX.

Keywords: Birch xylan, controlled acetylation, physico-mechanical properties, plasticizer, thermochemical properties.

\section{Introduction}

In order to develop a competitive substitute for oil-based non-biodegradable plastics, many studies have been carried out to prepare and improve the properties of films produced from renewable and biodegradable biopolymers (Gröndahl et al. 2003, 2004; Goksu et al. 2007; Mikkonen et al. 2009; Edlund et al. 2010; Escalante et al. 2012; Hansen et al. 2012; Mikkonen and Tenkanen, 2012; Stepan et al. 2012; Zhang et al. 2013; Egüés et al. 2013, 2014; Gordobil et al. 2014; Ibn Yaich et al. 2014; Stepan et al. 2014; Mikkonen et al. 2015; Svärd et al. 2015). In this scenario, birch xylan appears to be a strategic biopolymer for the Swedish industry. Currently, birch is the hardwood most used for industrial purposes in Sweden, accounting for approximately $12.4 \%$ of the total wood volume produced (SLU 2018). The industrial use of birch generates a considerable amount of xylan-rich waste, such as branches, sawdust and stumps. Birch xylan can also be generated as a by-product of industrial processes, for example, during the production of dissolving pulp for textiles, cellulose derivatives and ethanol, where the xylan accumulated both in waste and as a by-product has a great potential for novel and green applications (Mikkonen et al. 2015).

The properties of xylan generally depend on its natural chemical structure, which depends on its origin, and on the extraction method used for its isolation (Egüés et al. 2014). For film applications, however, a number of other factors must be considered to produce films with good properties and a coherent matrix. Such factors include, for example, the purity of the xylan sample (Goksu et al. 2007; Hansen et al. 2012), the choice of derivatization methods for the functionalization of the xylan structure (Gröndahl et al. 2003; Egüés et al. 2014; Gordobil et al. 2014; Stepan et al. 2014) and the use of plasticizers during film formation (Gröndahl et al. 2003; Escalante et al. 2012; Hansen et al. 2012; Gordobil et al. 2014).

Selective lignin removal is usually an important step during xylan preparation. For film formation, however, the limit of lignin content is not so strict. The presence of a certain amount of residual lignin in the xylan (approximately 1.0\%) has been shown to be beneficial for the formation 
of a coherent film from birch xylan (Goksu et al. 2007; Hansen et al. 2012) or from agricultural waste (Egüés et al. 2013). Alkaline extraction is largely used to produce high-yield xylan from holocellulose (delignified lignocellulosic biomass). The alkaline conditions also promote the removal of acetyl groups and, to a lesser extent, of uronic acid substitutions from xylan. The alkaline conditions also promote the disruption of intermolecular ester and ether bonds between xylan and other chemical components, including residual lignin (Egüés et al. 2014). Despite the selectivity of the method, some residual heteropolysaccharides other than xylan may still remain in the extracted fraction after alkaline treatment. To the best of our knowledge, no study which relating the presence of residual heteropolysaccharides in xylan to film formation has yet been published.

The derivatization of xylan by acetylation has been considered by several authors to be a strategic tool for improving the properties of xylan and, consequently, the properties of its films (Gröndahl et al. 2003; Egüés et al. 2014; Gordobil et al. 2014; Stepan et al. 2014). Different acetylation methods have been described (Zinbo and Timell 1965; Koroskenyi and McCarthy 2001; Lu and Ralph, 2003; Xu et al. 2010; Stepan et al. 2012; Zhang et al. 2012; Stepan et al. 2013; Zhang et al. 2016). Recently, a method using a combination of dimethyl sulfoxide (DMSO) and 1methylimidazole (or N-methylimidazole - NMI) has been suggested as an efficient method for dissolving lignocellulosic biomasses using relatively mild conditions ( $\mathrm{Lu}$ and Ralph, 2003; Zhang et al. 2012; Zhang et al. 2016). By acetylation, the hydroxyl groups in xylan are substituted by acetyl groups, and this improves properties of xylan such as thermal stability, mechanical strength and water resistance (Gröndahl et al. 2003; Egüés et al. 2014).

Several studies have reported difficulty in forming films using only xylan-rich material (Gröndahl et al. 2004; Goksu et al. 2007; Mikkonen et al. 2009; Hansen et al. 2012; Egüés et al. 2014; Mikkonen et al. 2015; Svärd et al. 2015). The addition of a plasticizers agent, such as carboxymethyl cellulose sodium salt, glycerol, methoxypolyethylene glycol, sorbitol or xylitol, has been suggested to improve film formation by reducing the brittleness and forming a coherent film matrix (Gröndahl et al. 2004; Goksu et al. 2007; Mikkonen et al. 2009; Edlund et al. 2010; Hansen et al. 2012; Zhang et al. 2013; Gordobil et al. 2014; Ibn Yaich et al. 2014; Mikkonen et al. 2015; Svärd et al. 2015). Although low molecular weight plasticizers are usually used, polymeric compounds, such as the carboxymethyl cellulose sodium salt, have also been reported to improve film formation from xylan (Edlund et al. 2010; Ibn Yaich et al. 2014; Svärd et al. 2015). Glycerol 
and xylitol have a favorable effect on the formation of coherent, transparent and flexible films from glucuronoxylan (Gröndahl et al. 2004), and glycerol also enables the formation of films with increased elongation films from cotton stalk xylan (Goksu et al. 2007) and lowers the glass transition temperature (Gröndahl et al. 2004; Zhang et al. 2013). In turn, the use of sorbitol as plasticizer during films formation has been reported to be more effective than glycerol in creating a water vapor barrier (Mikkonen et al. 2009) and preserving the thermal stability of the films (Hansen et al. 2012).

The aim of the present study was to improve the formation of films of birch xylans by controlled acetylation and to assess the effect of the degree of acetylation on the thermochemical and physico-mechanical properties of films prepared from such xylan samples. The effect of the use of different plasticizers (i.e., glycerol, sorbitol and xylitol) on the properties of film prepared from non-acetylated xylan was also investigated as an alternative to acetylation.

\section{Materials and methods}

\section{Materials}

Alkali-soluble xylan (ASX) prepared from extractives-free birch wood and commercial xylan (CX) from birch (Sigma, Germany) were used for the preparation of xylan films.

The following chemicals were used for controlled acetylation and film preparation: glacial acetic acid (100\%) (VWR, France), sodium acetate 99\% (Merck, USA), sodium chlorite 80\% (Alfa Aesar, Germany), acetone 99.5\% (VWR, France), polyester membrane (PES) (porosity $60 \mu \mathrm{m}$ ) (Monodur ${ }^{\circledR}$, Germany), potassium hydroxide lentils (Fisher Scientific, UK), formic acid 98/100\% (VWR, England), methanol HPLC grade (Fisher Chemicals, UK), dimethyl sulfoxide 99.5\% (DMSO) (Sigma-Aldrich, France), 1-methylimidazole >99\% (NMI) (Sigma-Aldrich, Germany), acetic anhydride (Sigma-Aldrich, Germany), absolute ethanol (VWR, France), chloroform (Fisher Scientific, UK), sorbitol (Sigma-Aldrich, Germany), glycerol (VWR Chemicals, France) and xylitol (Acros Organics, Belgium).

\section{Isolation of ASX sample}

For delignification, $10 \mathrm{~g}$ extractives-free birch wood was suspended in $388 \mathrm{~mL}$ of water, 15 $\mathrm{mL}$ of glacial acetic acid, $72 \mathrm{~mL}$ of sodium acetate $30 \%(\mathrm{w} / \mathrm{v})$ and $55 \mathrm{~mL}$ of sodium chlorite $30 \%$ $(\mathrm{w} / \mathrm{v})$ at $75^{\circ} \mathrm{C}$ under constant stirring. The reaction was kept for $30 \mathrm{~min}$ and additional glacial acetic 
acid, sodium acetate and sodium chlorite (same dosages) were added to the suspension up to a total of 3 reagent additions at $30 \mathrm{~min}$ intervals between additions. The suspension was then filtered using a polyester membrane and the holocellulose was washed with $5 \mathrm{~L}$ of distilled water followed by $100 \mathrm{~mL}$ of acetone and dried at room temperature $\left(24^{\circ} \mathrm{C}\right)$ (Magaton, 2008).

Thereafter, the holocellulose was used for xylan isolation. About $5 \mathrm{~g}$ holocellulose was added to $140 \mathrm{~mL}$ of $\mathrm{KOH} 24 \%(\mathrm{w} / \mathrm{w})$ and stirred at $24^{\circ} \mathrm{C}$ for $24 \mathrm{~h}$ under nitrogen (Hansson \& Hartler, 1968; Escalante et al. 2012). The suspension was then filtered using a polyester membrane and washed with $100 \mathrm{~mL}$ of distilled water, and the supernatant was added to $600 \mathrm{~mL}$ of ethanol at $\mathrm{pH} 3.5$ (adjusted with formic acid) and cooled overnight at $4^{\circ} \mathrm{C}$ so that the xylan precipitated. The precipitated xylan was recovered by centrifugation, washed with methanol and dried at room temperature $\left(24^{\circ} \mathrm{C}\right)$ (adapted from Hansson \& Hartler, 1968).

\section{Controlled acetylation of birch xylan at low and high degrees of acetylation}

Controlled acetylation of birch xylan was performed to obtain low and high degrees of acetylation. Birch xylan was placed in a dark bottle and DMSO and NMI were added in ratio of 22:2:1 (mg xylan:mL DMSO:mL NMI). The suspension was heated at $100^{\circ} \mathrm{C}$ for $5 \mathrm{~h}$ under nitrogen with constant stirring. After the initial heating, the solubilization of xylan in DMSO/NMI continued at room temperature and under constant stirring for a further $19 \mathrm{~h}$, resulting in a total time of $24 \mathrm{~h}$ for solubilization.

Acetic anhydride (Aa) was used as the esterifying agent in the acetylation reaction. It was assumed that $100 \mathrm{mg}$ dry xylan contains approximately $1.52 \mathrm{mmol}$ hydroxyl groups (Zhang et al. 2016), and different volumes of Aa were added to obtain low and high degrees of acetylation (0.425:1 $\mathrm{mol} \mathrm{Aa} / \mathrm{mol}$ hydroxyl groups in the xylan sample) (Table 1). Aa was added dropwise to the xylan suspension, and the reaction was kept under constant stirring for $24 \mathrm{~h}$, after that the acetylation reaction was quenched by cooling in an ice bath, and the xylan was precipitated by the addition of cold water and cold absolute ethanol (2.2:1:4 mg xylan/mL MilliQ- $\mathrm{H}_{2} \mathrm{O} / \mathrm{mL}$ EtOH), and cooling at $4^{\circ} \mathrm{C}$ overnight. Thereafter, the suspension was centrifuged and the xylan was recovered, washed with ethanol/water (80\% ethanol) and freeze-dried (adapted from $\mathrm{Lu}$ and Ralph 2003 and Zhang et al. 2016). 
Table 1. Acetylation parameters (color of xylan, Aa/xylan molar ratio and acetic anhydride volume), degree of acetylation, acetylation yield, number-average molar mass (Mn), weightaverage molar mass (Mw) and dispersity (D). The Mn, Mw and D parameters of ASX and CX acetylated at low degree were not determined (n.d).

\begin{tabular}{|c|c|c|c|c|c|c|c|c|}
\hline Sample & $\begin{array}{c}\text { Color of } \\
\text { xylan }\end{array}$ & $\begin{array}{c}\mathrm{Aa} / \mathrm{xylan} \\
\left(\mathrm{mol} \mathrm{mol}{ }^{-1}\right)\end{array}$ & $\begin{array}{c}\text { Acetic } \\
\text { anhydride } \\
(\mathrm{mL})\end{array}$ & $\mathrm{DS}_{\mathrm{Ac}} *$ & $\begin{array}{l}\text { Acetylation } \\
\text { yield (\%) }\end{array}$ & $\mathrm{Mn}, \mathrm{kDa}$ & $\mathrm{Mw}, \mathrm{kDa}$ & $\mathrm{D}$ \\
\hline \multirow{3}{*}{$\mathrm{CX}$} & Light yellow & - & - & $0.04 \pm 0.00$ & - & 6.6 & 17.7 & 2.8 \\
\hline & Brown & $0.4: 1$ & 0.25 & $0.58 \pm 0.03$ & 22 & n.d. & n.d. & n.d. \\
\hline & Dark brown & $25: 1$ & 16 & $1.59 \pm 0.04$ & 121 & 4.4 & 42.8 & 9.7 \\
\hline \multirow{3}{*}{ ASX } & Light yellow & - & - & - & - & 13.8 & 23.7 & 1.7 \\
\hline & Brown & $25: 1$ & 16 & $0.38 \pm 0.01$ & 89 & n.d. & n.d. & n.d. \\
\hline & Dark brown & $25: 1$ & 16 & $1.17 \pm 0.06^{* *}$ & $101 * * *$ & 9.0 & 35.4 & 3.9 \\
\hline
\end{tabular}

*[Degree of substitution with acetyl groups in the xylan structure].

$* *$ [To obtain the degree of acetylation of 1.17 , the ASX sample acetylated at degree of acetylation 0.38 was subjected to another acetylation process].

$* * *\left[\right.$ Combined yield of two acetylation steps: $1^{\text {st }}$ step $-89 \%$ and $2^{\text {nd }}$ step $\left.-114 \%\right]$.

n.d.: not determined

For ASX, an additional acetylation step was applied to the acetylated ASX to obtain the high degree of acetylation. The conditions for this extra acetylation were the same as those previously described. The acetylation process was performed in only one replication for each degree of acetylation.

\section{Preparation of films}

Non-acetylated xylan samples (birch ASX and birch commercial) were used for the preparation of films with and without plasticizer. Water-based films were prepared by stirring 300 mg xylan in $20 \mathrm{~mL}$ deionized water at $60^{\circ} \mathrm{C}$ for $3 \mathrm{~h}$. The suspension was then poured into a plastic Petri dish $(5.5 \mathrm{~cm}$ diameter $)$ and dried in an oven at $25^{\circ} \mathrm{C}$. Alternatively, two dosages of $20 \%$ or $40 \%$ (based on dry xylan weight) of plasticizer (glycerol, sorbitol or xylitol) were added to the aqueous xylan dispersions for film formation (Gröndahl et al. 2004; Hansen et al. 2012; Gordobil et al. 2014). The suspension (with or without plasticizer) was poured into a plastic Petri dish (5.5 $\mathrm{cm}$ diameter) and dried in an oven at $25^{\circ} \mathrm{C}$. In the case of low-acetylated xylan, the films were prepared by the same method but without any plasticizer.

Films of acetylated xylan with low and high degrees of acetylation (birch ASX and birch commercial) were cast in chloroform. In this case, $300 \mathrm{mg}$ acetylated xylan were stirred in $20 \mathrm{~mL}$ chloroform at room temperature for $3 \mathrm{~h}$, and the suspension was poured into a Teflon Petri dish 
( $6.0 \mathrm{~cm}$ diameter) and dried in a fume hood, covered by an inverted funnel.

When necessary, the dispersion of the xylan samples in the solvents was improved by sonication. Dried films (from non-acetylated and acetylated xylan samples) were conditioned at $23^{\circ} \mathrm{C}$ and $50 \%$ relative humidity for at least $24 \mathrm{~h}$ before testing. One film was prepared for each sample and plasticizer dosage.

\section{Thermochemical characterization of the xylan structure}

\section{Fourier transform infrared (FTIR) spectroscopy}

Acetylation of the xylan structure was initially confirmed by assessment of the functional groups in Fourier-transform infrared (FTIR) spectra. A Perkin-Elmer Spectrum 100 FTIR spectrometer equipped with a single reflection (ATR: attenuated total reflection) (Golden gate from Graseby Specac LTD, Kent, England) was used. Dry xylan samples were analyzed at room temperature in the range of $4000-600 \mathrm{~cm}^{-1}$ wavelength using 16 scans at a resolution of $4 \mathrm{~cm}^{-1}$ at intervals of $1 \mathrm{~cm}^{-1}$.

\section{Acetyl groups and degree of acetylation of xylan samples}

The content of acetyl groups in the xylan samples was determined as described by Bi et al. (2016). Acetylated xylan (approximately $7 \mathrm{mg}$ ) was placed in $2 \mathrm{~mL}$ Eppendorf tubes and suspended in $300 \mu \mathrm{L}$ MilliQ- $\mathrm{H}_{2} \mathrm{O}$. Sequentially, $1.2 \mathrm{~mL} 0.8 \mathrm{~mol} \mathrm{~L}^{-1}$ sodium hydroxide $(\mathrm{NaOH})$ and $10 \mu \mathrm{L} 1$ mol L ${ }^{-1}$ propionic acid (internal standard) were added, and the suspension was agitated at $60^{\circ} \mathrm{C}$ overnight for complete solubilization. The solution obtained was neutralized using $37 \% \mathrm{HCl}$ and filtered through Chromacol $(0.45 \mu \mathrm{m})$ filters into HPLC vials. The samples were analyzed by highperformance liquid chromatography (HPLC) (Dionex Sunnyvale, CA, USA) and detection by UV/Vis. Samples for the calibration curve were prepared using glacial acetic acid. The analysis was performed in duplicate.

The degree of acetylation $\left(\mathrm{DS}_{\mathrm{Ac}}\right)$ was determined from the content of acetyl groups $(\mathrm{Xu}$ et al. 2010) as:

$$
D S_{A c}=\frac{132 \times \% \text { acetyl }}{\left(M_{\text {acetyl }} \times 100\right)-\left(M_{\text {acetyl }}-1\right) \times \% \text { acetyl }}
$$

where $D S_{A c}$ is the degree of acetylation of the xylan samples, \% acetyl is the acetyl content 
determined by HPLC and $M_{\text {acetyl }}$ is the molecular weight of the acetyl group (43 $\left.\mathrm{g} \mathrm{mol}^{-1}\right)$.

\section{Klason lignin and sugar composition of xylan samples}

Klason lignin was determined after two sequential acid hydrolysis procedures. The xylan sample was initially subjected to acid hydrolysis using $72 \%$ sulfuric acid at room temperature for $1 \mathrm{~h}$. The acid concentration was then reduced to approximately $2.5 \%$ sulfuric acid using MilliQ$\mathrm{H}_{2} \mathrm{O}$, and the second acid hydrolysis was performed at $121^{\circ} \mathrm{C}$ for $1 \mathrm{~h}$. Thereafter, the suspension was filtered and washed with hot water, and the Klason lignin was recovered as the solid fraction and gravimetrically quantified according to the Tappi test method (T222 om-06) after drying in an oven at $105^{\circ} \mathrm{C}$. Klason lignin analysis was performed in duplicate.

The sugar composition of the xylan samples was determined by acid methanolysis analysis (De Ruiter et al. 1992; Bertaud et al. 2002; Willför et al. 2009; Appeldoorn et al. 2010). Approximately $1 \mathrm{mg}$ freeze-dried xylan was hydrolyzed in $1 \mathrm{~mL}$ of $2 \mathrm{~mol} \mathrm{~L}^{-1}$ hydrochloric acid $(\mathrm{HCl})$ in dry methanol at $100^{\circ} \mathrm{C}$ for $5 \mathrm{~h}$. Thereafter, the suspension was neutralized using pyridine and dried at room temperature under an inert gas. Another hydrolysis was then performed by the addition of $1 \mathrm{~mL}$ of $2 \mathrm{~mol} \mathrm{~L}^{-1}$ trifluoroacetic acid (TFA) at $120^{\circ} \mathrm{C}$ for $1 \mathrm{~h}$, after this which the suspension was again dried under an inert gas and finally dissolved in $1 \mathrm{~mL}$ of water $\left(\mathrm{MilliQ}-\mathrm{H}_{2} \mathrm{O}\right)$. The hydrolysates were analyzed by high-performance anion exchange chromatography with pulsed amperometric detection (HPAEC-PAD) using an ICS-3000 system (Dionex) equipped with a CarboPac PA1 column $(4 \times 250 \mathrm{~mm}$, Dionex) (Morais de Carvalho et al. 2017). Samples for calibration were prepared using standard sugars. Sugar analysis by methanolysis was performed in three replicates.

\section{Molecular weight}

The molecular weight of the xylan samples was determined by size exclusion chromatograpy (SEC) on a SECcurity 1260 system (Polymer Standard Services, Mainz, Germany) equipped with a refractive index (RI) detector (Polymer Standard Services, Mainz, Germany) coupled in series to a multiple-angle laser light scattering detector (MALLS; BIC-MwA7000, Brookhaven Instrument Corp., New York). $4 \mathrm{mg} / \mathrm{mL}$ xylan solution was prepared by dissolving the xylan directly in the SEC eluent $(0.5 \% \mathrm{LiBr}$ in $\mathrm{DMSO})$ for $16 \mathrm{~h}$ at $60^{\circ} \mathrm{C}$ under constant stirring. The solution was then filtered through $0.45 \mu \mathrm{m}$ PTFE syringe filters and analyzed by SEC. The 
samples were separated by GRAM columns (Polymer Standard Services, Mainz, Germany) where a PreColumn (50 x 8 mm, $10 \mu \mathrm{m}$ particle size), a $100 \AA$ column, and a $10000 \AA$ column $(300$ x 8 $\mathrm{mm}, 10 \mu \mathrm{m}$ particle size) were connected in series. The flow was $0.5 \mathrm{ml} / \mathrm{min}$, the column oven was at $60^{\circ} \mathrm{C}$, and the RI-detector at $40^{\circ} \mathrm{C}$. Nine pullulan standards with a Mp ranging between 342 and 708000 Da (Polymer Standard Services, Mainz, Germany) were used for standard calibration to determine the apparent molecular weight of the samples. The analysis was performed in duplicate.

Thermogravimetric analysis and differential scanning calorimetry of xylan samples and films prepared with addition of plasticizers

The thermogravimetric (TGA) properties of both xylan samples and films prepared with addition of plasticizers were assessed using a Mettler Toledo TGA/DSC 1 instrument coupled with a STAR ${ }^{\mathrm{e}}$ System. Samples, $2-8 \mathrm{mg}$, were first heated from 25 to $600^{\circ} \mathrm{C}$ at rate of $10^{\circ} \mathrm{C} \mathrm{min}^{-1}$ in nitrogen. The differential scanning calorimetry (DSC) analysis was performed using 2-6 mg of sample in a Mettler Toledo DSC 1 instrument coupled with a STARe System. Samples were heated at $10^{\circ} \mathrm{C} / \mathrm{min}$ from 25 to $105^{\circ} \mathrm{C}$ to remove moisture, and then after cooling to $25^{\circ} \mathrm{C}$, heated again from $25^{\circ} \mathrm{C}$ to $400^{\circ} \mathrm{C}$ in nitrogen (Egüés et al. 2014). The glass transition ( $\mathrm{T}_{\mathrm{g}}$ ) temperature was obtained from the second heating scan. Both the TGA and DSC analyses were performed in duplicate.

\section{Physico-mechanical properties of films}

\section{Physico-mechanical tests}

The physico-mechanical tests were performed in a room with controlled temperature $\left(23^{\circ} \mathrm{C}\right)$ and relative humidity $(50 \%)$ and the films were conditioned under these conditions for at least 24 $\mathrm{h}$ before testing. The weights, diameters and thicknesses of the xylan films were determined in accordance with SCAN-P 88:01. The mechanical properties were measured on $5 \mathrm{~mm}$ wide strips cut from the central part of the films using an Instron 5944 equipment with a $500 \mathrm{~N}$ load cell. The mechanical tests were performed with a free span between the clamps of $150 \mathrm{~mm}$ and a constant rate of elongation of $1.5 \mathrm{~mm} \mathrm{~min}^{-1}$. A total of 5 strips were measured for each sample.

\section{Transmittance}

Transmittance was measured at a wavelength of $800-200 \mathrm{~nm}$ on single xylan film sample 
using a Shimadzu UV-2550 (Japan) spectrophotometer, considering air as the reference.

\section{Results and Discussion}

\section{Acetylation of xylan samples: influence of reaction conditions}

Acetylation is a simple and efficient derivatization reaction which generates modified polysaccharides with specific thermochemical properties suitable for barrier applications (Gröndahl et al. 2003; Egüés et al. 2014; Gordobil et al. 2014; Stepan et al. 2014). To fairly assess how the degree of acetylation affects the preparation and properties of films, alkali-soluble birch xylan (ASX) and commercial birch xylan (CX) were acetylated to two different degrees, designated low (for values lower than 0.7 ) and high (for values higher then 1.0). Unlike the observation for the ASX sample, traces of acetyl groups were detected in the CX sample (Table 1), although they were imperceptible in the FTIR spectrum (absence of band at $1740 \mathrm{~cm}^{-1}$ ) (Figure 1), probably due to the low content.

The successive substitution of hydroxyl groups by acetyl groups during acetylation was confirmed by FTIR spectra based on the emergence and/or the increasing intensity of the band at $1740 \mathrm{~cm}^{-1}(\mathrm{C}=\mathrm{O}$ stretching) and the decrease in intensity of vibrations in the $\mathrm{OH}$-region (around 3750-3000 $\mathrm{cm}^{-1}$ ) (Bian et al. 2010; Belmokadden et al. 2011) (Figure 1). The OH-region is due to several stretching vibration of inter- and intra-molecular hydrogen bonds (Popescu et al. 2011; Djikanović et al. 2016), e.g., involving the $\mathrm{O}(2) \mathrm{H}$ and the $\mathrm{O}(3) \mathrm{H}$ in the xylan chain. The combination of such vibrations causes a broadening of the $\mathrm{OH}$ region in the FTIR spectra (Popescu et al. 2011). The substitution of hydroxyl by acetyl groups was also corroborated by other bands: at $1364 \mathrm{~cm}^{-1}$, assigned to the $\mathrm{C}-\mathrm{CH}_{3}$ stretching, at $1210 \mathrm{~cm}^{-1}$, due to the $\mathrm{C}-\mathrm{O}$ stretching, and at 1426 $\mathrm{cm}^{-1}$, due to the asymmetric aliphatic $\mathrm{C}-\mathrm{H}$ deformation of the methyl group (Drobniak; Mastalerz, 2006; Belmokaddem et al. 2011). Typical bands for polysaccharides were observed at 2946 (C-H stretching vibration), 1608 (water absorption), 1034 (C-O and C-C stretching or C-OH bending) and $896 \mathrm{~cm}^{-1}$ ( $\beta$-glycosidic linkage) (Gupta et al. 1987; Kačuráková et al. 1998; Rodrigues et al. 1998; Rodrigues et al. 2001; Chaikumpollert et al. 2004; Sun et al. 2004). 

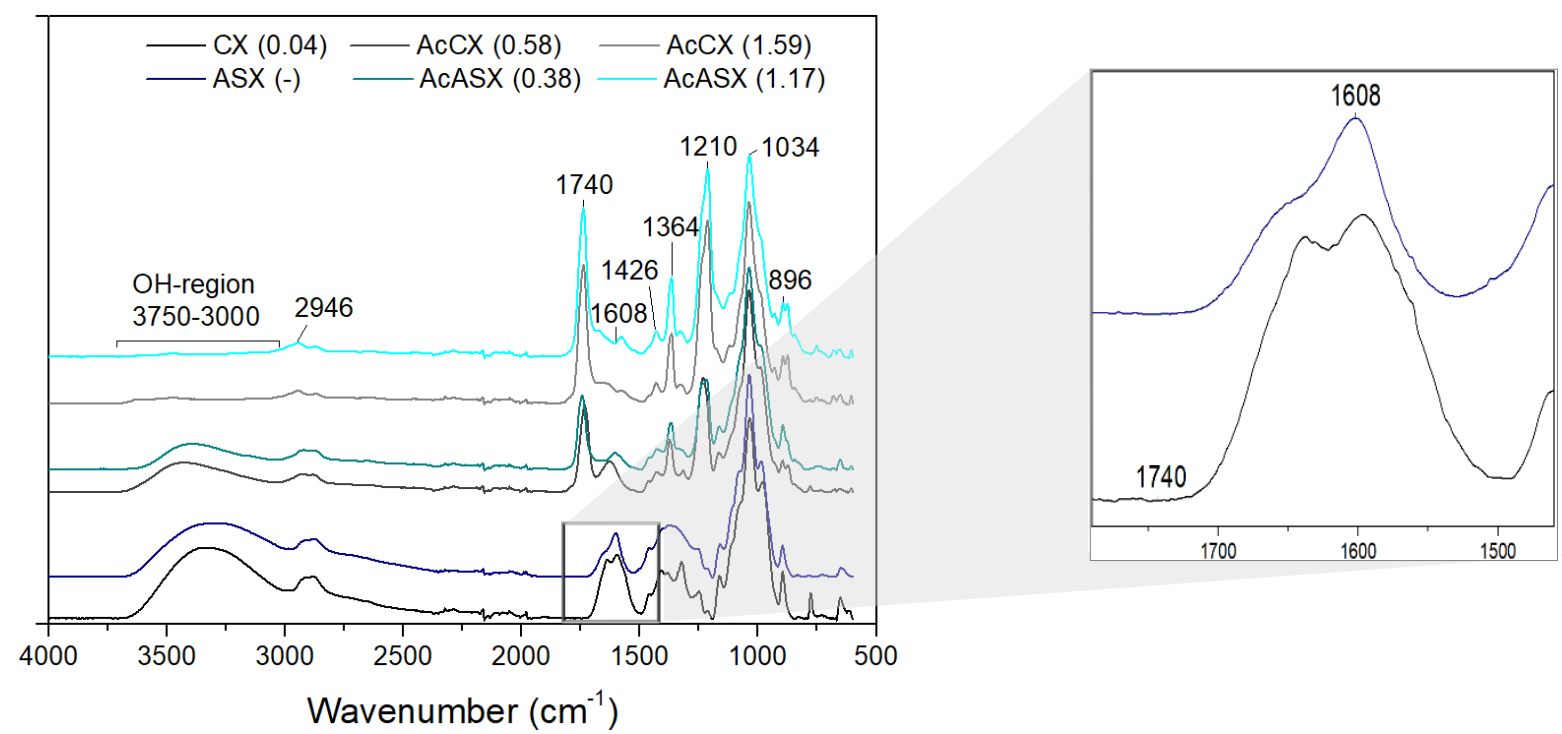

Figure 1. FTIR spectra of ASX and CX samples non-acetylated and acetylated at low $(0.38-0.58)$ and high (1.17-1.59) degrees.

The ASX and CX materials differed in terms of reactivity during the acetylation, the CX sample being clearly more reactive. For the ASX sample, two steps of acetylation were necessary to achieve a high degree of acetylation (1.17), but for the CX sample only one acetylation step was required, resulting in a degree of acetylation of 1.59 with a yield of $121 \%$ (Table 1 ). To obtain a lower degree of acetylation (0.38) of the ASX sample, the Aa:xylan molar ratio was kept at 25:1 $\left(\mathrm{mol} \mathrm{mol}^{-1}\right)$, but the Aa:xylan molar ratio was reduced to $0.4: 1\left(\mathrm{~mol} \mathrm{~mol}^{-1}\right)$ to obtain the degree of acetylation of 0.58 for the CX sample. Surprisingly, in this case, the xylan recovery was only $22 \%$, suggesting that most of the low-acetylated CX was soluble in ethanol (Peng et al. 2009).

Comparing the acetylation parameters of ASX and CX, three important features can be pointed out: 1) the limited reactivity of the ASX sample; 2) increase in the ASX reactivity by acetylation after sequential acetylation; and 3) a decrease in the yield of xylan during the acetylation process, resulting in a yield below 100. As a rule, the substitution of hydroxyl groups (low molar mass) by acetyl groups (high molar mass) should increase the final xylan mass, and our results suggested that there was some loss of xylan during the first acetylation step of ASX. This was probably due to the increased solubility of a certain xylan fraction in the ethanol used in the final xylan recovery step. During the second acetylation step, on the other hand, a gain in xylan mass was observed, indicating a good recovery yield. The molecular weight of the CX was slightly lower than that of ASX material, and acetylation increased the molecular weights of both ASX and CX 
probably due to the introduction of the larger acetyl groups and, as a result, the change in the hydrodynamic volume of the xylan. After acetylation, the xylan formed less aggregates in solution than the non-acetylated xylan.

The darkening of the acetylated xylan samples could due to side reactions between xylan and the solvent system used for acetylation (i.e, the DMSO/NMI), and to side reactions between the solvent system and the esterifying agent (i.e., the acetic anhydride). It has been reported earlier, that at elevated temperature and prolonged contact, NMI can form colored condensed products and adducts with terminal reduced end units of polysaccharides (Ebner et al. 2008; Liebner et al. 2010). Stepan et al. (2013) studied the acetylation of rye xylan in the ionic liquid 1-alkyl-3methylimidazolium under various conditions. A brown product was usually obtained after a long reaction time (e.g. $16 \mathrm{~h}$ ) at $50^{\circ} \mathrm{C}$, whereas a white product was obtained when the reaction time was only 5 minutes. The authors suggested that, when possible, the acetylation time should be reduced to obtain a white acetylated xylan. In addition, when mixed with certain alkylation or acylating agents (e.g. the acetic anhydride used for acetylation in the present study) DMSO may result in oxidation of hydroxyl groups in cellulose according to a mechanism similar to the Swern oxidation process (Henniges et al. 2007). A similar effect of DMSO on the hemicelluloses was suggested by Haimer et al. (2010) due to the introduction of keto groups into the polymer and the potentially formation of colored compounds. A short reaction time and low derivatization temperature were shown to minimize the extent of oxidation, but oxidation cannot be completely avoided when DMSO-based mixtures are used (Henniges et al. 2007).

\section{Impact of acetylation on the chemical composition of xylan samples}

The monosaccharide composition of the xylan samples was monitored during acetylation, and the results are shown in Table 2. The presence of xylose and glucuronic acid (GlcA) in the structure of glucuronoxylan from birch has been reported elsewhere (Teleman et al. 2002; Ebringerová et al. 2005). As expected, these two monosaccharides represented more than $89 \%$ of the sugars in the xylan samples, the highest amount being in the CX samples (higher than 97\%). Interestingly, the acetylation process seemed to lead to a purification of the xylan samples, especially the ASX sample. Before acetylation, the ASX sample contained approximately $10.6 \%$ heteropolysaccharides (defined here as monosaccharides from polymers other than xylan), mainly galactose (Gal) (2.3\%) and galacturonic acid (GalA) (3.2\%). After the first acetylation step (DS 
0.38), the amount of heteropolysaccharides decreased to $9.5 \%$, of which $2.0 \%$ and $2.3 \%$ were Gal and GalA, respectively. The reduction of the heteropolysaccharide content was even greater after the second acetylation step. Highly acetylated ASX (DS $\left.\operatorname{Dc}_{\mathrm{Ac}} 1.17\right)$ contained $7.4 \%$ heteropolysaccharides (1.0\% Gal and 2.3\% GalA). Although only $2.8 \%$ heteropolysaccharides were found in the CX sample, the trend for purification to occur during acetylation was also observed.

The presence of monosaccharides from heteropolysaccharides other than xylan in CX and ASX can be explained by the coextraction of residual pectin substances together with xylan during the isolation processes. Pectins are a known group of substances present in plants that may contain polysaccharides such as galacturonan, rhamnogalacturonan, arabinan and galactans (Sjöström and Westermark 1999). The coextraction of heteropolysaccharides was apparently favored by the alkaline conditions used for xylan isolation in the present study, leading to a less pure ASX sample.

Similar contents of residual Klason lignin were observed in the CX (1.2\%) and ASX (1.4\%) samples. According to Goksu et al. (2007), a small amount of lignin in a xylan sample can be beneficial to the formation of a coherent films, especially for lignin contents around $1.0 \%$.

Table 2. Monosaccharides composition of xylan samples monitored during the acetylation process. Values in parenthesis refer to the average degree of acetylation obtained by HPLC. Values in parenthesis refers to the degree of acetylation of the samples.

\begin{tabular}{lcccccc}
\hline \multirow{2}{*}{$\begin{array}{c}\text { Monosaccharides } \\
(\%)\end{array}$} & \multicolumn{7}{c}{ Samples } \\
\cline { 2 - 7 } Xylose & CX $(0.04)$ & AcCX $(0.59)$ & AcCX (1.59) & ASX (-) & AcASX (0.38) & AcASX (1.17) \\
\hline Glucuronic acid & 96.5 & 96.8 & 97.3 & 86.8 & 89.1 & 91.6 \\
\hline Arabinose & 0.7 & 0.6 & 0.8 & 2.7 & 1.4 & 1.0 \\
\hline Glucose & 0.0 & 0.0 & 0.0 & 0.3 & 0.4 & 0.2 \\
\hline Mannose & 0.4 & 0.7 & 0.3 & 2.1 & 2.5 & 2.3 \\
\hline Galactose & 0.0 & 0.0 & 0.0 & 1.7 & 1.5 & 0.9 \\
\hline Galacturonic acid & 0.3 & 0.2 & 0.2 & 2.3 & 2.0 & 1.0 \\
\hline Ramnose & 2.1 & 1.7 & 1.3 & 3.2 & 2.3 & 2.3 \\
\hline Xylan* & 0.0 & 0.0 & 0.1 & 1.0 & 0.9 & 0.6 \\
\hline
\end{tabular}

*[Sum of xylose and glucuronic acid contents].

\section{Films formation: preparation and visual aspects}

As suggested in the literature, water was used for film preparation from non-acetylated xylan (CX and ASX) (Gröndahl et al. 2004; Goksu et al. 2007; Mikkonen et al. 2009; Egüés et al. 2014; Gordobil et al. 2014) and chloroform was used for the casting of films of the highly 
acetylated xylan (Stepan et al. 2012; Stepan et al. 2013; Zhang et al. 2013; Egüés et al. 2014; Gordobil et al. 2014). The formation of a film from ASX acetylated to a low degree of acetylation was tested in both water and chloroform. Due to the low yield and insufficient amount of sample obtained for the CX with a low degree of acetylation, this sample was not used for film preparation. To improve the dispersability of xylan in the solvents, sonication was used in combination with stirring (chloroform-based films) (Gordobil et al. 2014) and stirring/heating (water-based films).

Images of the xylan films are presented in Figure 2. The color of the films followed the color of the xylan samples; light yellow for non-acetylated samples and darker (brown) with increasing degrees of acetylation. Non-coherent and brittle films were formed from the nonacetylated CX samples without and with plasticizer, regardless of the type and charge of the plasticizer used (Figure 2a). Since all the CX-films showed a similar behavior, only the CX-film without plasticizer is shown in Figure 2a. The inability to form films from birch wood xylan has been reported by Hansen et al. (2012), who attributed this to the low amount of Klason lignin $(0.6 \%)$ in the birch wood xylan sample. According to Goksu et al. (2007) a residual content of around $1.0 \%$ Klason lignin seems to be required to allow film formation from cotton stalk xylan. It is expected that some interactions and crosslinks between lignin and xylan, common in cell walls, may be unaffected when a certain amount of lignin is preserved in xylan samples, improving their subsequent film formation (Hansen et al. 2012). Our results revealed, however, similar Klason lignin contents in CX (1.2\%) and ASX (1.4\%), indicating that factors other than the lignin content had affected the film formation. This argument was corroborated by the successful formation of films from ASX samples with and without plasticizer (Figure 2c). Since all ASX-films were visually similar, only the ASX-film without plasticizer is presented in Figure 2c. The fundamental difference between the CX and the ASX samples was the significantly greater amount of heteropolysaccharides in the ASX samples. This was originally assumed to be a problem, but instead it improved the formation of the film. Gröndahl et al. (2004) asserted that the shortness of the xylan chain is a factor that compromises film formation. According to our results, the presence of pectin heteropolysaccharides in the xylan fractions apparently acted as an internal plasticizer during film formation. ASX containing heteropolysaccharides formed coherent, transparent and homogeneous films. The presence of such heteropolysaccharides in the xylan fractions improved the film formation probably by increasing the dispersibility of the xylan in water. Finally, our results proved not only that residual lignin improves the formation of xylan films but also that the presence 
of a certain amount of heteropolysaccharides is also beneficial.

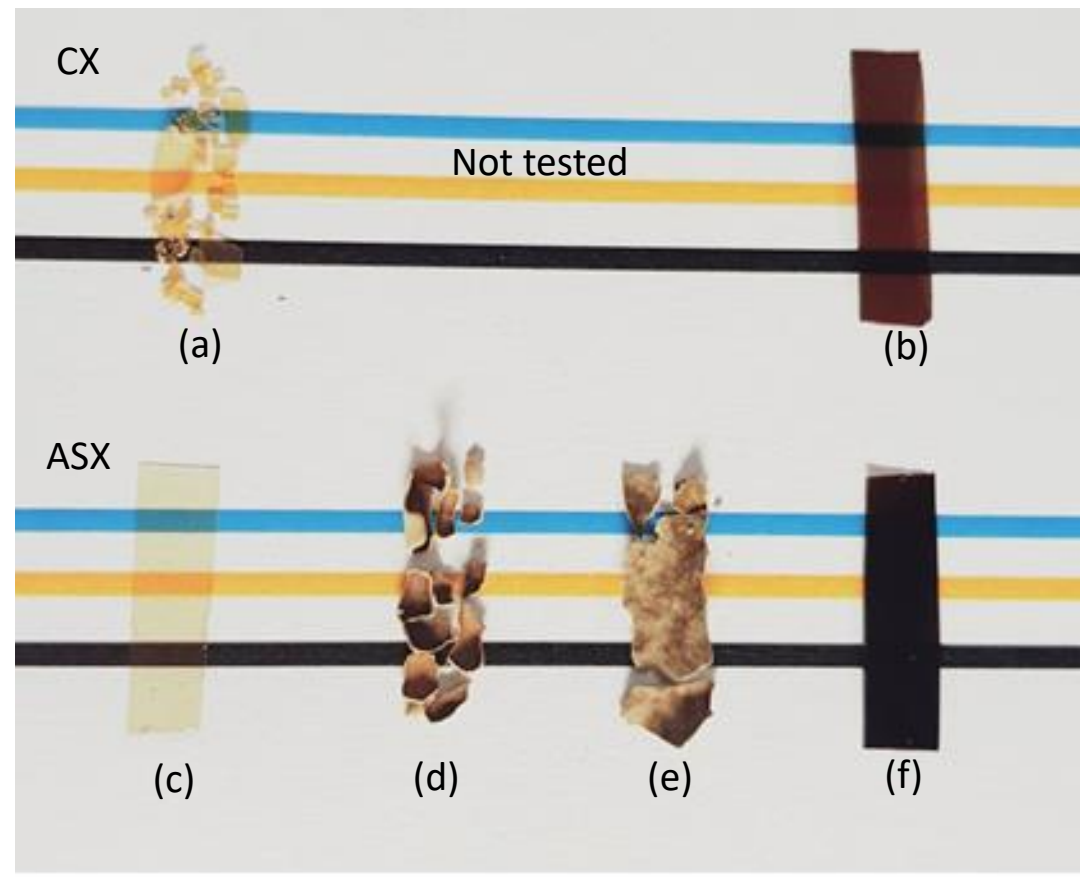

Figure 2. Birch films prepared using non-acetylated CX in water (a), high-acetylated CX in chloroform (b), non-acetylated ASX in water (c), low-acetylated ASX in water (d), low-acetylated ASX in chloroform (e) and high-acetylated ASX in chloroform (f). The colored rows in the background were used for viewing the transparency of the strips of films.

The free hydroxyl groups of xylan have been derivatized by several researchers to favor film formation (Gröndahl et al. 2003; Stepan et al. 2012; Egüés et al. 2014). However, the ASX acetylated to a low degree of acetylation did not form a coherent film either in water or in chloroform (Figures $2 \mathrm{~d}$ and $2 \mathrm{e}$ ). The low degree of modification probably created two distinct polarities in the xylan structure, preventing interaction with water by the acetylated fraction and interaction with chloroform by the non-acetylated fraction. Good interactions with chloroform were observed only in xylan samples with a degree of acetylation higher than 1.0. Both CX and ASX samples with a high degrees of acetylation formed coherent films. The acetylated CX sample formed a transparent and homogeneous film (Figure 2b), but the acetylated ASX sample formed an opaquer and heterogeneous film, with light and dark regions (Figure 2f). It is known that the market prefers transparent films and coatings, especially for food packaging. However, Hansen et 
al. (2012) have stated that the current demand does not exclude the use of dark films, and other properties of films such as physico-mechanical and thermal properties should therefore be assessed.

\section{Properties of films}

\section{Physico-mechanical properties}

The effect of plasticizers on the physico-mechanical properties of ASX-films was investigated, glycerol, sorbitol and xylitol being added in two dosages: $20 \%$ or $40 \%$. The films prepared using the ASX in the presence or absence of a plasticizers were equally transparent and were identical in appearance. The transparency of the ASX-films (with or without plasticizer) was confirmed by the high transmittance results obtained at a wavelength of $550 \mathrm{~nm}$ (an arbitrary value chosen in the middle of the visible wavelength range) (Figure 3). Although the transmittance of all the ASX-films was in the same range (67.7\%-75.6\%), sorbitol preserved the transparency of the films better than the other plasticizers. In general, the use of $40 \%$ plasticizer reduced the transparency of the films compared with films prepared without plasticizer, regardless of the plasticizer used.

The acetylated CX-film, which was colored and translucent, had a transmittance value of $12.7 \%$, which was much higher than that of acetylated ASX-film (1.5\%) that was not only colored, but also opaque and heterogeneous.

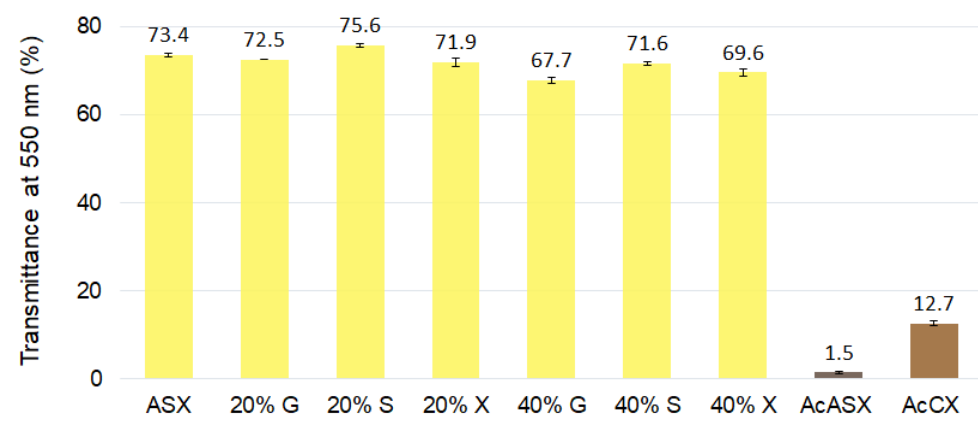

Figure 3. Transmittance values measured at the wavelength of $550 \mathrm{~nm}$. The results refer to the films prepared with ASX, ASX in the presence of $20 \%$ or $40 \%$ of glycerol (G), sorbitol (S) and xylitol (X), acetylated ASX (AcASX) and acetylated CX (AcCX).

The physical aspects of the films varied depending on the dosage of plasticizer and 
acetylation (Table 3). As expected, an increase in the dosage of plasticizer increased the thickness of the films. The dosage of plasticizer also led to a variation in the diameter of the films (ASX $=$ $4.7 \mathrm{~cm}$, with $20 \%$ plasticizer $=5.2 \mathrm{~cm}$, and with $40 \%$ plasticizer $=4.8 \mathrm{~cm}$ ). This variation can be explained by the differences in the shrinkage processes caused by the evaporation of water during the film formation (Gröndahl et al. 2004). As a consequence, the higher plasticizer dosage resulted in an increase in the grammage of the films. The density of the films increased when $40 \%$ glycerol or sorbitol was used, but decreased with $40 \%$ xylitol. Much lower values of thickness, grammage and density were observed for films prepared using acetylated xylans.

Differences in the dosage of plasticizer and acetylation resulted in different mechanical properties of the films (Table 3). The films prepared from the ASX sample, although coherent, were extremely stiff and brittle and had the highest observed value of the Young's modulus (2.4 GPa) and the lowest strain-at-break (0.8\%) (Table 3). When 20\% plasticizer was added, both the tensile strength and the strain-at-break increased. Hansen et al. (2012) observed a similar improvement in mechanical properties using $20 \%$ sorbitol, but a reduction in tensile strength when glycerol was used. The flexibility of the films was also improved, result confirmed by the Young's modulus reduction to the range of 1.4-1.8 GPa. However, the improvement in mechanical properties was not sufficient to create a plastic behavior in the films (Figure 4), which can limit their application. Plastic behavior was only observed in films with $40 \%$ plasticizer, regardless of the type of plasticizer (Figure 4). Despite a clear reduction in the tensile strength compared with films prepared using $20 \%$ plasticizer, those prepared using $40 \%$ plasticizer showed a greater strain-at-break (9.6$16.9 \%$ ) with a reduction in the Young's modulus to $0.3-0.8 \mathrm{GPa}$. Similar results were reported by Hansen et al. (2012). A dosage of $40 \%$ plasticizer allowed film elongation without the film simply breaking, and the best mechanical properties were obtained with $40 \%$ addition of sorbitol or xylitol. Our results were similar to those obtained by other authors (Gröndahl et al. 2004; Mikkonen et al. 2009). Gröndahl et al. (2004) also observed that increasing the sorbitol and xylitol dosage from $20 \%$ to $40 \%$ resulted in a decrease in tensile strength and an increase in elongation at break in xylan films. Comparing glycerol and sorbitol at a dosage of 40\%, Mikkonen et al. (2009) also reported that xylan films prepared using glycerol had a lower tensile strength and Young's modulus. 
Table 3. Summary of physico-mechanical properties of birch xylan films

\begin{tabular}{ccccccc}
\hline Samples & $\begin{array}{c}\text { Thickness } \\
(\mu \mathrm{m})\end{array}$ & $\begin{array}{c}\text { Grammage } \\
\left(\mathrm{g} \mathrm{m}^{-2}\right)\end{array}$ & $\begin{array}{c}\text { Density } \\
\left(\mathrm{kg} \mathrm{m}^{-3}\right)\end{array}$ & $\begin{array}{c}\text { Tensile } \\
\text { strength } \\
(\mathrm{MPa})\end{array}$ & $\begin{array}{c}\text { Strain-at- } \\
\text { break }(\%)\end{array}$ & $\begin{array}{c}\text { Young's } \\
\text { modulus } \\
(\mathrm{GPa})\end{array}$ \\
\hline ASX & $93.3 \pm 1.3$ & $145.3 \pm 2.1$ & $1456 \pm 33$ & $19.3 \pm 1.4$ & $0.8 \pm 0.1$ & $2.4 \pm 0.2$ \\
\hline ASX 20\% G & $113.0 \pm 1.3$ & $171.9 \pm 3.1$ & $1478 \pm 43$ & $26.2 \pm 4.7$ & $3.3 \pm 0.1$ & $1.4 \pm 0.1$ \\
\hline ASX 20\% S & $114.3 \pm 1.6$ & $180.0 \pm 0.1$ & $1481 \pm 5$ & $24.2 \pm 4.6$ & $1.6 \pm 0.3$ & $1.8 \pm 0.1$ \\
\hline ASX 20\% X & $113.3 \pm 0.7$ & $174.8 \pm 2.6$ & $1458 \pm 31$ & $25.5 \pm 1.0$ & $2.0 \pm 0.2$ & $1.6 \pm 0.1$ \\
\hline ASX 40\% G & $124.1 \pm 1.8$ & $209.4 \pm 2.8$ & $1547 \pm 16$ & $6.1 \pm 0.7$ & $9.6 \pm 0.4$ & $0.3 \pm 0.0$ \\
\hline ASX 40\% S & $115.4 \pm 0.8$ & $204.6 \pm 1.5$ & $1568 \pm 13$ & $17.6 \pm 0.6$ & $16.7 \pm 1.0$ & $0.8 \pm 0.0$ \\
\hline ASX 40\% X & $114.5 \pm 2.4$ & $220.4 \pm 3.5$ & $1415 \pm 6$ & $14.1 \pm 1.1$ & $16.9 \pm 2.0$ & $0.6 \pm 0.0$ \\
\hline AcASX & $89.1 \pm 1.6$ & $103.3 \pm 0.6$ & $1188 \pm 22$ & $30.8 \pm 1.5$ & $2.1 \pm 0.1$ & $1.8 \pm 0.0$ \\
\hline AcCX & $78.0 \pm 0.8$ & $87.9 \pm 0.3$ & $1204 \pm 9$ & $14.6 \pm 2.6$ & $0.7 \pm 0.1$ & $1.9 \pm 0.2$ \\
\hline
\end{tabular}

Acetylation gave only a slight improvement in the mechanical properties of birch ASX films, in contrast to that reported by Egüés et al. (2014) using corncob arabinoxylan. The Young's modulus values for acetylated films were similar to those obtained using $20 \%$ plasticizer in the ASX sample (AcASX - 1.8 GPa and AcCX - 1.9 GPa), indicating that the flexibility gained by acetylation can also be gained by using $20 \%$ plasticizer (glycerol, sorbitol or xylitol). The strainat-break values of acetylated ASX (2.1\%) and acetylated CX (0.7\%) were comparable to those observed for films prepared using non-acetylated ASX with 20\% plasticizer (1.6-3.3\%) and without plasticizer $(0.8 \%)$. The results obtained in the present study for the tensile strength and tensile strain of acetylated films were much lower than those reported for acetylated arabinoxylan (Egüés et al. 2014; Stepan et al. 2014). On the other hand, the lower Young's modulus obtained in this study suggested the formation of more flexible acetylated films than those reported by the aforementioned authors. The greater tensile strength and strain-at-break observed for ASX films than for CX films was probably another positive effect of the presence of heteropolysaccharides in the xylan sample. This result suggested that such heteropolysaccharides improved not only the film formation but also the mechanical properties of the films. 

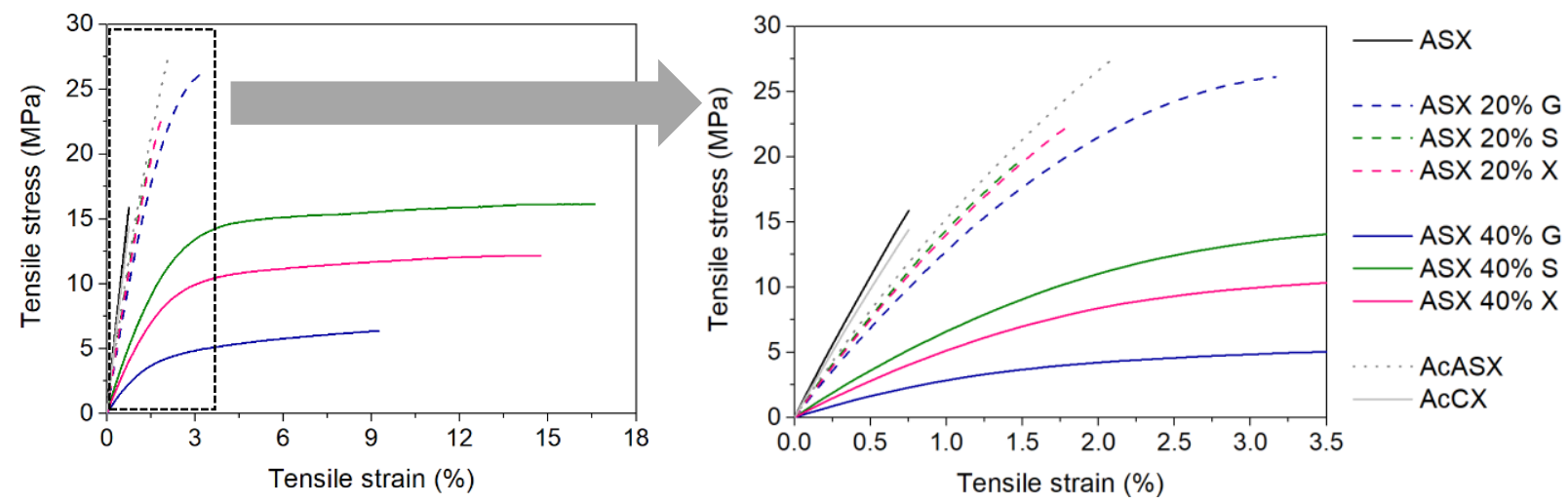

Figure 4. Stress-strain curves of films made of non-acetylated and acetylated ASX and CX samples in presence of absence of plasticizers.

The use of plasticizer can compensate for the need for acetylation in ASX in the development of mechanical properties. However, plasticizers not bound to the polymer and with low molecular weight, such as glycerol, sorbitol and xylitol, may migrate from the film during use (Svärd et al. 2015). This migration can be a problem in, for example, food-packaging, and migration of components from films to the food should not occur with chemically bonded acetylation.

In the present study, only $20 \%$ and $40 \%$ dosages of glycerol, sorbitol and xylitol were investigated. A plateau in the ratio between stress and strain in the plastic region was observed for films prepared using $40 \%$ plasticizer, regardless of the plasticizer used (Figure 4). These results not only confirmed the plastic behavior of those films but also indicated the possibility of optimization of plasticizer dosages between $20 \%$ and $40 \%$. The plastic behavior of films prepared with $40 \%$ plasticizer was accompanied by a lower glass transition temperature $\left(\mathrm{T}_{\mathrm{g}}\right)$ (Table 4$)$.

\section{Thermal properties}

The thermal stabilities of the xylan samples and their respective films prepared with addition of plasticizers were characterized by thermogravimetric analysis (TGA) and differential scanning calorimetry (DSC) and the main results are summarized in Table 4 and Figure 5. An increase in the glass transition temperature $\left(\mathrm{T}_{\mathrm{g}}\right)$ was observed as a result of acetylation, but plasticizer reduced the $T_{g}$ and increased the film flexibility (Egüés et al. 2013).

A loss of water was identified in the TGA spectra between $25^{\circ} \mathrm{C}$ and $100^{\circ} \mathrm{C}$ (Figure 5). Both 
acetylation and the use of plasticizer (especially xylitol) reduced the water content of the films (Table 4). Our results confirmed those in the literature, where a reduction in water absorption was observed after acetylation (Gröndahl et al. 2003).

Table 4. Thermogravimetric properties of xylan samples and their respective films prepared with addition of plasticizers

\begin{tabular}{|c|c|c|c|c|c|c|}
\hline \multirow{2}{*}{ Sample } & \multirow{2}{*}{$\frac{\left[25-100^{\circ} \mathrm{C}\right]}{\text { wt. }(\%)}$} & \multicolumn{3}{|c|}{$\left[150-450^{\circ} \mathrm{C}\right]$} & \multirow{2}{*}{$\begin{array}{c}\text { Residues at } 600^{\circ} \mathrm{C} \text {, } \\
\text { wt. } *(\%)\end{array}$} & \multirow{2}{*}{$\mathrm{Tg},{ }^{\circ} \mathrm{C}$} \\
\hline & & Onset $\left({ }^{\circ} \mathrm{C}\right)$ & wt.* $(\%)$ & T peak $\left({ }^{\circ} \mathrm{C}\right)$ & & \\
\hline \multicolumn{7}{|c|}{ Xylan samples } \\
\hline ASX & $7.7 \pm 0.0$ & $188.9 \pm 0.1$ & $49.9 \pm 0.3$ & $272.2 \pm 0.7$ & $32.8 \pm 0.6$ & $129.9 \pm 1.0$ \\
\hline AcASX & $0.3 \pm 0.0$ & $312.3 \pm 0.1$ & $81.3 \pm 0.6$ & $353.3 \pm 0.2$ & $14.2 \pm 0.8$ & $192.8 \pm 0.4$ \\
\hline $\mathrm{CX}$ & $4.2 \pm 0.5$ & $200.6 \pm 0.4$ & $60.3 \pm 0.5$ & $294.1 \pm 0.1$ & $31.5 \pm 0.1$ & $131.7 \pm 0.8$ \\
\hline $\mathrm{AcCX}$ & $0.6 \pm 0.1$ & $318.5 \pm 1.3$ & $82.6 \pm 1.3$ & $355.5 \pm 0.4$ & $11.2 \pm 1.4$ & $206.3 \pm 0.9$ \\
\hline \multicolumn{7}{|c|}{ Films prepared with addition of plasticizers } \\
\hline ASX $20 \% \mathrm{G}$ & $3.1 \pm 0.1$ & $179.2 \pm 0.0$ & $66.9 \pm 1.0$ & $272.2 \pm 2.2$ & $31.0 \pm 2.0$ & $127.9 \pm 0.5$ \\
\hline ASX $20 \% \mathrm{~S}$ & $3.1 \pm 0.1$ & $185.5 \pm 0.3$ & $67.1 \pm 1.8$ & $273.9 \pm 0.5$ & $29.4 \pm 1.7$ & $137.2 \pm 1.8$ \\
\hline ASX $20 \% \mathrm{X}$ & $2.8 \pm 0.0$ & $184.1 \pm 0.5$ & $67.6 \pm 1.1$ & $274.8 \pm 0.6$ & $28.9 \pm 2.0$ & $136.8 \pm 2.3$ \\
\hline ASX $40 \% \mathrm{G}$ & $3.5 \pm 0.1$ & $167.9 \pm 3.3$ & $71.6 \pm 2.3$ & $267.6 \pm 0.0$ & $25.8 \pm 2.4$ & $116.3 \pm 1.2$ \\
\hline ASX $40 \% \mathrm{~S}$ & $3.0 \pm 0.0$ & $179.0 \pm 1.5$ & $70.9 \pm 0.0$ & $281.9 \pm 0.9$ & $26.1 \pm 0.0$ & $117.0 \pm 0.8$ \\
\hline ASX $40 \% \mathrm{X}$ & $2.7 \pm 0.2$ & $177.8 \pm 1.5$ & $71.1 \pm 0.7$ & $277.8 \pm 3.6$ & $25.9 \pm 0.5$ & $121.0 \pm 1.5$ \\
\hline
\end{tabular}

The thermal degradation of the xylan itself and of the plasticizers was observed in the TGA spectra between $150^{\circ} \mathrm{C}$ and $450^{\circ} \mathrm{C}$. The derivative thermogravimetric curves (the lower left corners of the graphs in Figure 5) were used to determine the thermal stability of the samples, i.e., the temperature at which the main xylan degradation starts $\left(\mathrm{T}_{\text {onset }}\right)$. Thermal stability is a crucial parameter for films in food packaging, especially for extrusion processing and in applications where the product is to be microwaved (Mikkonen and Tenkanen 2012). A significant increase in the thermal stability of xylan was observed as a result of acetylation of $\operatorname{ASX}\left(\Delta \mathrm{T}_{\text {onset }}=123^{\circ} \mathrm{C}\right)$ and $\mathrm{CX}\left(\Delta \mathrm{T}_{\text {onset }}=118^{\circ} \mathrm{C}\right)$ samples (Table 4). Similar behavior has been previously reported (Egüés et al. 2014). The temperature at which the maximum rate of decomposition ( $\mathrm{T}$ peak) occurred increased with increasing degree of acetylation for $\operatorname{ASX}\left(\Delta \mathrm{T}_{\mathrm{T} \text { peak }}=81^{\circ} \mathrm{C}\right)$ and $\mathrm{CX}\left(\Delta \mathrm{T}_{\mathrm{T} \text { peak }}=61^{\circ} \mathrm{C}\right)$ samples, but the degradation became faster. The acetylated xylan produced significantly less residue at $600^{\circ} \mathrm{C}$ (char + ash) than the non-acetylated xylan, the greatest mass loss due to xylan degradation being observed between $150^{\circ} \mathrm{C}$ and $450^{\circ} \mathrm{C}$ (Table 4).

A reduction in the thermal stability of the films was observed when the plasticizers were 
used (Table 4 and Figure 5). Hansen et al. (2012) explained that this is probably due to a plasticization of the matrix of the film, which results in the breaking of intermolecular forces in the film during heating. A higher plasticizer dosage lowered the thermal stability and the lowest value was obtained with glycerol. Similar results were reported by Hansen et al. (2012) when comparing glycerol and sorbitol. Films prepared with $40 \%$ plasticizer left less residue at $600^{\circ} \mathrm{C}(25.8 \%-26.1 \%)$ than those prepared with $20 \%$ plasticizer $(28.9 \%-31.0 \%)$ or without plasticizer $(32 \%)$. This is probably due to the evaporation of the plasticizer during the thermogravimetric analysis (Hansen et al. 2012).
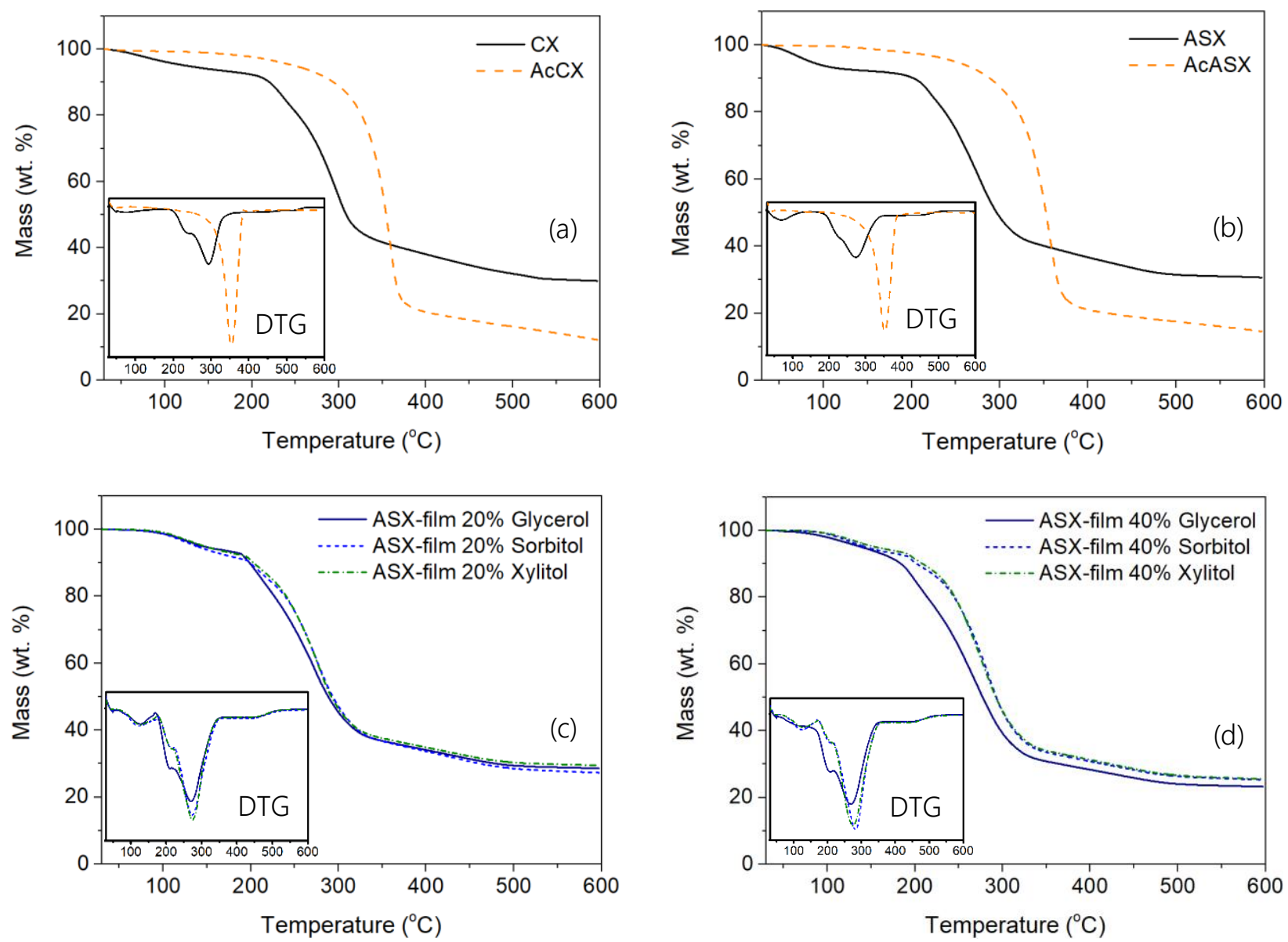

Figure 5. Thermal decomposition and derivative thermogravimetric curves (DTG) of xylan samples and films prepared using plasticizers, named: non-acetylated and acetylated CX (a), non-acetylated and acetylated ASX (b), non-acetylated ASX-films with $20 \%$ plasticizer (c) and non- acetylated ASX-films with $40 \%$ plasticizer (d). 


\section{Conclusions}

The reactivity of xylan samples during acetylation was impaired by the greater amount of residual heteropolysaccharides in the ASX sample (11\%). Acetylation led to a reduction in the amount of residual heteropolysaccharides in xylan samples, especially in the ASX sample.

The residual heteropolysaccharides acted as natural plasticizers during film formation, and their preservation in the ASX sample enhanced the formation of coherent, but brittle films. The use of external plasticizers (20\% and $40 \%)$ improved the flexibility and strength of the films, but only $40 \%$ plasticizer was efficient to achieve plastic behavior in the films. Acetylation favored film formation and improved the mechanical properties of the films to values similar to those obtained using $20 \%$ plasticizer. The use of plasticizers for preparing films is thus an alternative to acetylation for improving the mechanical properties. This strategy allows the preparation of films from water as solvent, without penalizing the film properties. External plasticizers not bound to the xylan may migrate out from the film during use, but this risk is avoided with xylan chemically modified by acetylation.

\section{Acknowledgements}

Danila Carvalho thanks the Wood and Pulping Chemistry Research Network (WPCRN) project for their financial support. Jennie Berglund acknowledges the Knut and Alice Wallenberg foundation for funding through the Wallenberg Wood Science Center at the KTH Royal Institute of Technology.

\section{References}

Appeldoorn, M. M., Kabel, M. A., Van Eylen, D., Gruppen, H., Schols, H. A. (2010). Characterization of oligomeric xylan structures from corn fiber resistant to pretreatment and simultaneous saccharification and fermentation. J. Agr. Food Chem. 58, 11294-11301.

Belmokaddem, F-Z., Pinel, C., Huber, P., Petit-Conil, M., Da Silva Perez, D. (2011) Green syntesis of xylan hemicellulose ester. Carbohyd. Res. 346:2896-2904.

Bertaud, F., Sundberg, A., Holmbom, B. (2002). Evaluation of acid methanolysis for analysis of wood hemicelluloses and pectins. Carbohyd. Polym. 48, 319-324.

Bi, R., Berglund, J., Vilaplana, F., McKee, L.S., Henriksson, G. (2016) The degree of acetylation affects the microbial degradability of mannans. Polym. Degrad. Stabil. 133: 36-46. 
Bian J., Peng, F., Xu, F., Sun, R-C., Kennedy, J. F. (2010) Fractional isolation and structural characterization of hemicelluloses from Caragana korshinskii. Carbohyd. Polym. 80:753-760.

Chaikumpollert, O., Methacanon, P., Suchiva, K. (2004) Structural elucidation of hemicelluloses from Vetiver grass. Carbohyd. Polym. 57:191-196.

De Ruiter, G.A., Schols, H.A., Voragen, A.G.J., Rombouts, F.M. (1992) Carbohydrate analysis of water-soluble uronic acid containing polysaccharides with high-performance anion-exchange chromatography using methanolysis combined with TFA hydrolysis is superior to four other methods. Analytical Biochemistry 207:176-185.

Djikanović, D., Devečerski, A., Steinbach, G., Simonović, J., Matović, B., Garab, G., Kalauzi, A., Radotić, K. (2016) Comparison of macromolecular interactions in the cell walls of hardwood, softwood and maize by fluorescence and FTIR spectroscopy, differential polarization laser scanning microscopy and X-ray diffraction. Wood Sci. Technol. 50:547-566.

Drobniak, A., Mastalerz, M. (2006) Chemical evolution of Miocene wood: Example from the Belchatow brown coal deposit, central Poland. International Journal of Coal Geology 66:157178.

Ebner, G., Schiehser, S., Potthast, A., Rosenau, T. (2008) Side reaction of cellulose with common 1-alkyl-3-methylimidazolium-based ionic liquids. Tetrahedron Lett. 49:7322-7324.

Ebringerová, A., Hromádková, Z., and Heinze, T. (2005) Hemicelluloses. Adv. Polym. Sci. 186:167.

Edlund, U., Ryberg, Y.Z., Albertsson, A-C. (2010) Barrier films from renewable forestry waste. Biomacromolecules 11:2532-253.

Egüés, I., Stepan, A., Eceiza, Labidi, J. (2013) Effect of different hemicelluloses characteristics on film forming properties. Ind. Crop. Prod. 47:331-338.

Egüés, I., Stepan, A.M., Eceiza, A., Toriz, G., Gatenholm, P., Labidi, J. (2014) Corncob arabinoxylan for new materials. Carbohyd. Polym. 102:12-20.

Escalante, A., Gonçalves, A., Bodin, A., Stepan, a., Sandström, C., Toriz, G., Gatenholm, P. (2012) Flexible oxygen barrier films from spruce xylan. Carbohyd. Polym. 87:2381-2387.

Goksu, E.I., Karamanlioglu, M., Bakir, U., Yilmaz, L., Yilmaze, U. (2007) Production and characterization of rilms from cotton stalk xylan. J. Agric. Food Chem. 55: 10685-10691.

Gordobil, O., Egüés, I., Urruzola, I., Labidi, J. (2014) Xylan-cellulose films: Improvement of hydrophobicity, thermal and mechanical properties. Carbohyd. Polym. 112:56-62. 
Gröndahl, M., Eriksson, L., Gatenholm, P. (2004) Material properties of plasticized hardwood xylans for potential application as oxygen barrier films. Biomacromolecules 5(4):1528-1535.

Gröndahl, M., Teleman, A. Gatenholm, P. (2003) Effect of acetylation on the material properties of glucuronoxylan from aspen wood. Carbohyd. Polym. 53:359-366.

Gupta, S., Madan, R. N., Bansal, M. C. (1987) Chemical composition of Pinus caribaea hemicellulose. Tappi J. 70(8):113-114.

Haimer, E., Wendland, M., Potthast, A., Henniges, U., Rosenau, T., Liebner, F. (2010) Controlled precipitation and purification of hemicellulose from DMSO and DMSO/water mixtures by carbon dioxide as anti-solvent. The Journal of Supercritical Fluids 53:121-130.

Hansen, N. M., Plackett, D. (2008) Sustainable films and coatings from hemicelluloses: a review. Biomacromolecules 9(6):1493-1505.

Hansen, N.M.L., Blomfeldt, T.O.J., Hedenqvist, M.S., Plackett, D.V. (2012) Properties of plasticized composite films prepared from nanofibrillated cellulose and birch wood xylan. Cellulose 19:2015-2031.

Hansson, J-Å. and Hartler, N. (1968) Alkaline degradation of xylans from birch and pine. Svensk Papperstidning 71(9):358-365.

Henniges, U., Kloser, E., Patel, A., Potthast, A., Kosma, P., Fischer, M., Fischer, K., Rosenau, T. (2007) Studies on DMSO-containing carbanilation mixtures: chemistry, oxidations and cellulose integrity. Cellulose 14:497-511.

Ibn Yaich, A., Edlung, U., Albertsson, A-C. (2014) Adapting wood hydrolysates barriers to high humidity conditions. Carbohyd. Polym. 100:125-142.

Kačuráková, M., Belton, P. S., Wilson, R. H., Hirsch, J., Ebringerová, A. (1998) Hydration properties of xylan-type structures: an FTIR study of xylooligosaccharides. J. Sci. Food Agric. 77:38-44.

Koroskenyi, B., McCarthy, S.P. (2001) Synthesis of acetylated konjac glucomannan and effect of degree of acetylation on water absorbancy. Biomacromolecules 2:824-826.

Liebner, F., Patel, I., Ebner, G., Becker, E., Horix, M., Potthast, A., Rosenau, T. (2010) Thermal aging of 1-alkyl-3-methylimidazolium ionic liquids and its effect on dissolved cellulose. Holzforschung 64:161-166.

Lu, F., Ralph, J. (2003) Non-degradative dissolution and acetylation of ball-milled plant cell walls: high-resolution solution-state NMR. The Plant Journal 35:535-544. 
Magaton, A. da S. (2008) Comportamento e caracterização de xilanas durante a polpação kraft de eucalipto. Federal University of Minas Gerais, pp. 259 (PhD thesis).

Mikkonen, K.S., Heikkinen, S., Soovre, A., Peura, M., Serimaa, R., Talja, R.A., Helén, H., Hyvönen, L., Tenkanen, M. (2009) Films from oat spelt arabinoxylan plasticized with glycerol and sorbitol. J. Appl. Polym. Sci. 114:457-466.

Mikkonen, K.S., Tenkanen, M. (2012) Sustainable food-packaging materials based on future biorefinery products: Xylan and mannans. Trends Food Sci. Tech. 28:90-102.

Mikkonen, K.S., Laine, C., Kontro, I. Talja, R.A., M., Serimaa, L., Tenkanen, M. (2015) Combination of internal and externa plasticization of hydroxypropylated birch xylan tailors the properties of sustainable barrier films. Eur. Polym. J. 66:307-318.

Morais de Carvalho, D., Martínez-Abad, A., Evtuguin, D. V., Colodette, J. L., Lindström, M. E., Vilaplana, F., Sevastyanova, O. (2017) Isolation and characterization of acetylated glucuronoarabinoxylan from sugarcane bagasse and straw. Carbohyd. Polym. 156:223-234.

Papescu, M-C., Papescu, C-M., Lisa, G., Sakata, Y. (2011) Evaluation of morphological and chemical aspects of different wood species by spectroscopy and thermal methods. Journal of Molecular Structure 988(1-3):65-72.

Peng, F., Ren, J-L., Xu, F., Bian, J., Peng, P., Su, R-C. (2009) Comparative Study of Hemicelluloses Obtained by Graded Ethanol Precipitation from Sugarcane Bagasse. J. Agric. Food. Chem. 57:6305-6317.

Rodrigues, J., Faix, O., Pereira, H. (1998) Determination of lignin composition of Eucalyptus globulus wood by FTIR spectroscopy. Holzforschung 52:46-50.

Rodrigues, J., Puls, J., Faix, O., Pereira, H. (2001) Determination of monosaccharide composition of Eucalyptus globulus wood by FTIR spectroscopy. Holzforschung 55:265-269.

Sjöström, E., Westermark, U. (1999) Chemical composition of wood and pulps: basic constituents and their distribution. In: Analytical Methods in Wood Chemistry, Pulping, and Papermaking. Eds. Sjöström, E., Alén, R. Springer-Verlag, Heidelberg. pp. 1-19.

SLU, Sveriges officiella statistic (2018). Skogsdata 2018. [Online] Umeå. Available at: https://www.slu.se/globalassets/ew/org/centrb/rt/dokument/skogsdata/skogsdata_2018_webb.pd f [Accessed 27 August 2018].

Stepan, A.M., Ansari, F., Berglund, L., Gatenholm, P. (2014) Nanofribrillated cellulose reinforced acetylated arabinoxylan films. Compos. Sci. Technol. 98:72-78. 
Stepan, A.M, Höije, A., Schols, H.A., Waard, P.de, Gatenholm, P. (2012) Arabinose content of arabinoxylans contributes to flexibility of acetylated arabinoxylan films. J. Appl. Polym. Sci. $125: 2348-2355$.

Stepan, A.M., King, A.W.T., Kakko, T., Toriz, G., Kilpeläinen, I., Gatenholm, P. (2013) Fast and highly efficient acetylation of xylans in ionic liquid systems. Cellulose 20:2813-2824.

Sun, J. X., Sun, X. F., Sun, R. C., Su, Y. Q. (2004) Fractional extraction and structural characterization of sugarcane bagasse hemicelluloses. Carbohyd. Polym. 56:195-204.

Svärd, A., Brännvall, E., Edlun, U. (2015) Rapeseed straw as a renewable source of hemicelluloses: Extraction, characterization and film formation. Carbohyd. Polym. 113:179-186.

Tappi standard (2011) T 222. Om-06, Acid-insoluble lignin in wood and pulp.

Teleman, A., Tenkanen, M., Jacobs, A., Dahlman, O. (2002) Characterization of $O$-acetyl-(4-Omethylglucurono)xylan isolated from birch and beech. Carbohyd. Res. 337:373-377.

Willför, S., Pranovich, A., Tamminen, T., Puls, J., Laine, C., Suurnäkki, A., Saake, B., Uotila, K., Simolin, H., Hemming, J., Holmbom, B. (2009) Carbohydrate analysis of plant materials with uronic acid-containing polysaccharides - A comparison between different hydrolysis and subsequent chromatographic analytical techniques. Ind. Crop. Prod. 29:571-580.

Xu, C, Leppären, A-S., Eklund, P., Holmlund, P., Sjöholm, R., Sundberg, K., Willför, S. (2010) Acetylation and characterization of spruce (Picea abies) galactoglucomannans. Carbohyd. Res. 345:810-816.

Zinbo, M., Timell, T.E. (1965) The degree of branching of hardwood xylans. Svensk Papperstidning 68:647-662.

Zhang, A.P., Liu, C.F., Sun, R.C., Xie, J., Chen, X.Y. (2012) Homogeneous acylation of eucalyptus wood at room temperature in dimethyl sulfoxide/N-methylimidazole. Bioresource Technol. 125:328-331.

Zhang, X., Zhang, A., Liu, C. and Ren, J. (2016) Per-O-acylation of xylan at room temperature in dimethylsulfoxide/N-methylimidazole. Cellulose 23:2863-2876.

Zhang, Y., Li, J., Lindström, M.E., Stepan, A., Gatenholm, P. (2013) Spruce glucomannan: Preparation, structural characteristics and basic film forming ability. Nord. Pulp Pap. Res. J. 28(3):323-330. 